\title{
Incidental Finding of Retroaortic Renal Vein 'Posterior Nutcracker Phenomenon' Associated with Thrombosis
}

\section{Achado Incidental de Veia Renal Retroaórtica "Fenômeno de Quebra-Nozes Posterior" Associada à Trombose}

Milton Sérgio Bohatch Júnior', Amanda Fernandes Vidal da Silva², Carlos Diego Ribeiro Centellas', Maurício Serra Ribeiro ${ }^{2}$ Edwaldo Edner Joviliano ${ }^{2}$

${ }^{1}$ Department of Vascular and Endovascular Surgery, Hospital das Clínicas of the Faculty of Medicine, University of São Paulo, Ribeirão Preto, SP, Brazil. ${ }^{2}$ Department of Vascular and Endovascular Surgery, Hospital de Base, Rio Preto, SP, Brazil.

A 56-year-old woman was admitted to the emergency room with acute obstructive abdomen. She denied comorbidities or previous surgeries. Abdominal computed tomography showed cecal volvulus and an incidental finding of chronic recanalized left renal vein thrombosis with a retroaortic trajectory (posterior "nutcracker" phenomenon). She underwent exploratory laparotomy with a right colectomy and transverse ileum anastomosis. After a gradually progressed diet, she was discharged from hospital ten days after surgery. In outpatient follow-up, she denied symptoms of abdominal or flank pain, and laboratory tests showed no signs of proteinuria or hematuria. Conservative treatment and periodic follow-up were chosen considering the incidental finding of nutcracker phenomenon.

A retroaortic left renal vein is a rare anatomical variation that is asymptomatic in most cases and called posterior nutcracker phenomenon. In symptomatic cases, the term posterior nutcracker syndrome is used. ${ }^{1,2}$ Its exact prevalence is unknown, but it is more commonly diagnosed in female patients between the third and fourth decades of life. ${ }^{1}$ This compressive disorder can result in venous hypertension with renal vein dilation and ureteral and renal pelvis varicose veins and present as macroscopic and microscopic hematuria, flank pain, and proteinuria. ${ }^{2,3}$ Conservative treatment is used for asymptomatic or oligosymptomatic patients as described in here. ${ }^{2}$

\section{Authors' contributions}

Research creation and design: Bohatch Júnior MS, Silva AFV; Data acquisition: Bohatch Júnior MS, Centellas CDR; Data analysis and interpretation: Bohatch Júnior MS, Silva AFV, Centellas CDR, Joviliano EE ; Manuscript writing: Bohatch Júnior MS, Silva AFV; Critical revision of the manuscript for important intellectual content Bohatch Júnior MS, Ribeiro MS, Joviliano EE.

\section{Conflict of interest}

The authors have declared that they have no conflict of interest.

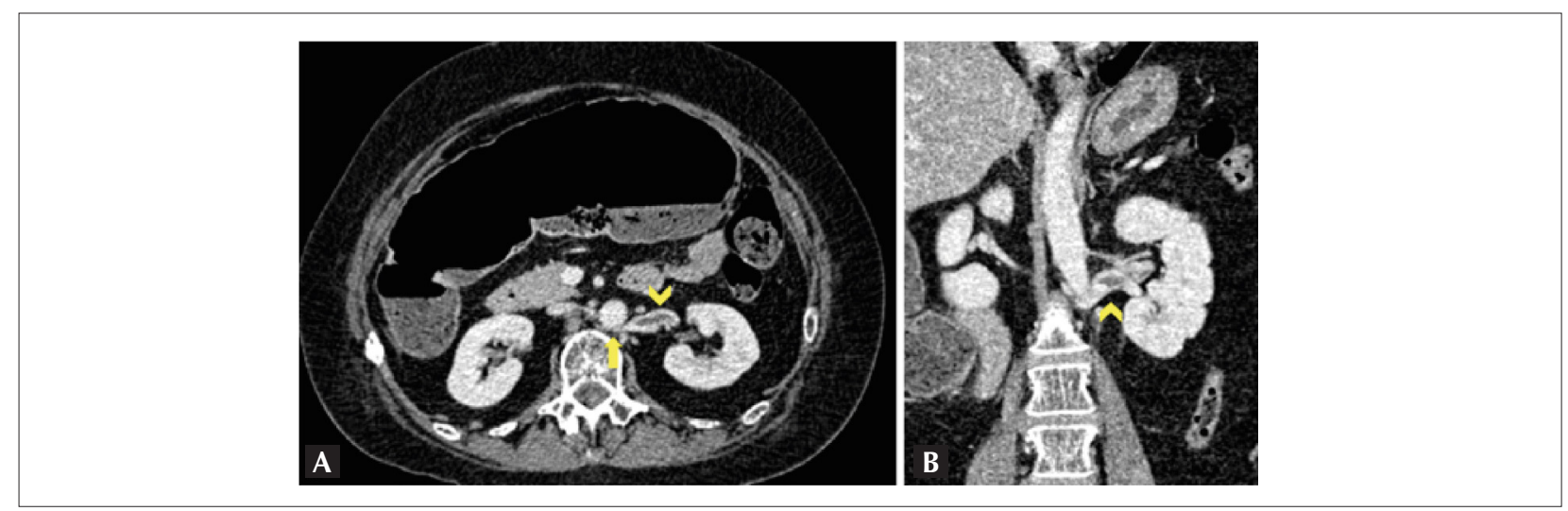

Figure 1 - Contrast-enhanced abdominal tomography image. (A) Axial section revealing a dilated left renal vein (arrowhead) with a retroaortic trajectory, causing clamping (arrow). (B) Coronal section also revealing a dilated left renal vein (arrowhead).

\section{Keywords}

Incidental Findings; Renal Nutcracker Syndrome; Thrombosis.

Mailing Address: Milton Sergio Bohatch Junior •

milton.j87@hotmail.com

Manuscript received 4/6/2020; revised 5/7/2020; accepted 5/11/2020

DOI: 10.47593/2675-312X/20213404eabc104 


\section{Images}

\section{References}

1. Pulgarin Ricardo LG, Isaza Zapata S, Uribe Gonzalez R. Left inferior vena cava with nutcracker syndrome: A case report. Radiol Case Rep. $2017 \mathrm{Nov}$ 6;13(1):32-34. doi: 10.1016/j.radcr.2017.10.007

2. Ananthan K, Onida S, Davies AH. Nutcracker syndrome: an update on current diagnostic criteria and management guidelines. Eur J Vasc Endovasc Surg. 2017;53(6):886-94. doi: 10.1016/j.ejvs.2017.02.015

3. Chait A, Matasar KW, Fabian CE, Mellins HZ. Vascular impressions on the ureters. Am J Roentgenol Radium Ther Nucl Med. 1971;111(4):729-49. doi: 10.2214/ajr.111.4.729

4. de Macedo GL, Dos Santos MA, Sarris AB, Gomes RZ. Venous revascularization to treat posterior nutcracker syndrome by transposition of the left gonadal vein: case report. J Vasc Bras. 2019;18:e20190037. doi: 10.1590/1677-5449.190037 